\title{
Instalação da Disciplina de Atenção Básica em Saúde na Faculdade de Medicina da Universidade de São Paulo (2003-2006)
}

\author{
Implementation of the discipline Basic \\ Care at the Faculty of Medicine of the \\ University of São Paulo
}

\author{
Joaquim Edson Vieira ${ }^{1}$ \\ Paulo Eduardo Mangeon Elias ${ }^{2}$ \\ Isabela Judith Martins Benseñor ${ }^{2}$ \\ Sandra Josefina Elero Grisi ${ }^{2}$
}

PALAVRAS-CHAVE:

-Educação Médica;

- Atenção Primária à Saúde;

- Sistemas de Saúde.

KEY-WORDS:

- Education, Medical;

- Primary Health Care;

- Community Health Planning.

Recebido em: 31/08/2006

Reencaminhado em: 14/03/2007

Aprovado em: 08/05/2007

\section{R E S U M O}

Introdução: A disciplina de Atenção Básica em Saúde constitui um programa interdepartamental na Faculdade de Medicina da USP, apoiada por três Unidades Básicas de Saúde com o Programa de Saúde da Família. Este estudo avalia sua instalação. Métodos: Questionários de avaliação de ambiente, Delphi e de auto-avaliação com escala de capacidades. Resultados: Cento e sessenta e dois primeiranistas em 2004 (93\%), 142 em 2005 (81\%) e 129 terceiranistas (74\%) responderam. Orientar a utilização dos serviços de saúde, visitar famílias, promover saúde, oferecer suporte e identificar situações de risco, entre primeiranistas, e "consulta médica com adultos" e "reunião de grupo com pacientes", com alunos do terceiro, alcançaram o nível "fiz o procedimento com ajuda de alguém". Capacidades adquiridas: realidade social e de saúde, trabalho do agente comunitário, entendimento do Programa de Saúde da Família, Atenção Primária e Sistema de Saúde. As percepções de ambiente diferiram entre os locais ou equipes. Discussão: As avaliações sugerem razoável conhecimento e capacitação para o trabalho dos agentes comunitários. $O$ vocabulário dos alunos incorporou SUS, PSF e Atenção Básica. Conclusão: A disciplina alcançou avaliação positiva no seguimento de pessoas, famílias e comunidades.

\section{A B S T R A C T}

Introduction: The discipline Basic Care is an interdepartmental program of the Faculty of Medicine of the São Paulo University, supported by three local Basic Care Units offering the Family Health Program. This study evaluates its implementation. Methods: Questionnaires aimed at evaluation of the environment, Delphi and self-assessment with a competence scale. Results: One hundred and sixty two freshmen in 2004 (93\%), 142 in 2005 (81\%) and 129 third year students (74\%) responded. Among the freshmen, provide orientation about how to use the health services, household visits and health promotion, offer support and identify risk situations, and among the third year students "medical appointments with adults" and "group meetings with patients" reached the level "procedure performed with guidance of somebody". Acquired capacities were sense of the social and health reality, perform Health Agent functions and understand the Family Health Program, Basic Care and Health System. The perception of the environment differed between local Units or Teams. Discussion: The evaluation suggested reasonable capacity for performing the functions of a Health Agent. The terms Health System, Family Health Program and Basic Care were part of the vocabulary of the students. Conclusion: The discipline reached a positive evaluation with regard to following-up individuals, families and the community. 


\section{INTRODUÇÃO}

A Faculdade de Medicina da Universidade de São Paulo (FMUSP) tradicionalmente vem utilizando o Hospital das Clínicas, grande complexo hospitalar-universitário, e o Hospital Universitário da USP como principais unidades de ensino. Em ambos, durante o internato, os alunos do curso médico têm treinamento ambulatorial e hospitalar, em disciplinas clínicas e cirúrgicas. Um dos desafios da FMUSP é o de, garantindo a graduação de excelência, compô-la com suas características de inclinação pela pesquisa científica e abrangente atividade assistencial especializada do Hospital das Clínicas.

O atual projeto pedagógico da FMUSP considera fundamental que o curso médico atenda as principais demandas de saúde da sociedade e proveja a formação humanística e socialmente responsável de seu profissional. No projeto pedagógico atual, o médico que a FMUSP pretende formar segue as linhas das Diretrizes Curriculares Nacionais do Curso de Graduação em Medicina ${ }^{1}$. Em seu preâmbulo, inclui o treinamento nos três níveis de atenção à saúde (primário, secundário e terciário) e propõe que o aluno exerça a profissão com responsabilidade social e competência técnica.

No segmento nuclear, o currículo abrange conhecimentos, habilidades e atitudes necessários à formação geral do médico para todos os alunos de Medicina; no segmento complementar ou das optativas, oferece a oportunidade para o exercício da autonomia e iniciativa dos alunos no sentido de complementarem sua formação.

O segmento nuclear corresponde a $80 \%$ da carga horária do primeiro ao oitavo semestres do curso. O segmento complementar corresponde a até $20 \%$ da carga horária, do primeiro ao oitavo semestres. Possui atividades diversificadas: de iniciação científica, estágios de formação profissional, disciplinas optativas, atividades de monitorias e de extensão de serviços à comunidade. Nos dois últimos anos (internato) não há atividades optativas, embora sua necessidade deva ser reconhecida.

Um aspecto das diretrizes do projeto pedagógico ainda não completamente atendido refere-se à Atenção Primária à Saúde. Por conseqüência, pode-se inferir que a intersecção da FMUSP com o Sistema de Saúde apresenta essa carência. A disciplina de Atenção Básica em Saúde proposta em 2003 se estabeleceu como programa interdepartamental e transcurricular, abrangendo os Departamentos de Medicina Preventiva, Clínica Médica, Pediatria, e Ginecologia e Obstetrícia e se expressa no currículo no primeiro, segundo, sexto, nono e décimo semestres. As atividades de planejamento pedagógico contam com a participação das chefias das Unidades Básicas de Saúde envolvidas. Também se busca estabelecer um convênio entre a USP e a Prefeitura
Municipal de São Paulo para garantir a continuidade desta cooperação recomendada pelas Diretrizes Curriculares Nacionais para os cursos de Graduação em Medicina. Concomitantemente, a Diretoria da FMUSP criou a Comissão de Educação Permanente em Atenção Primária à Saúde, sob coordenação do vice-diretor, para assessorar e atender a execução das atividades demandadas à instituição.

A disciplina está implantada em Unidades Básicas de Saúde do Distrito do Butantã. Esta região da cidade de São Paulo foi escolhida por ser a região do campus da USP na qual se encontra o Hospital Universitário, que constitui unidade de referência para a rede municipal de saúde de modo a compatibilizar a integração de serviços. O objetivo deste estudo é avaliar a instalação e evolução da disciplina de Atenção Básica em Saúde na Faculdade de Medicina da USP como projeto interdepartamental e transcurricular.

\section{MÉTODOS}

O treinamento dos alunos está fundamentalmente ligado às equipes do Programa de Saúde da Família (PSF). A disciplina se apóia em três Unidades Básicas de Saúde (UBS) - Jardim Boa Vista, Vila Dalva e Parque São Jorge -, totalizando 15 Equipes de Saúde da Família (ESF). Durante todo o desenvolvimento atual, no primeiro e terceiro anos, um docente acompanha um grupo de 15 alunos nas atividades desenvolvidas em cada UBS. A disciplina contempla as seguintes atividades em 432 horas:

- Nos dois semestres iniciais (primeiro ano), os alunos têm um período semanal de atividades, no qual acompanham as atividades dos agentes de saúde, realizam o reconhecimento do território, mantêm o primeiro contato com a situação de saúde local e desenvolvem projetos de ação em saúde na comunidade em interação com os profissionais das ESF. As visitas domiciliares - posteriormente - e os projetos de ação em saúde - previamente - são discutidos em horário protegido durante a realização da disciplina. A carga horária anual é de 160 horas.

- No sexto semestre (terceiro ano), os alunos têm um período semanal de atividades nas mesmas UBS, correspondendo a 80 horas. Acompanham as atividades da equipe do PSF na Unidade, participando do planejamento e das atividades de promoção da saúde e prevenção de riscos e agravos e do trabalho da enfermagem e dos agentes de saúde. Realizam visitas domiciliares com autonomia para medidas e registros de sinais vitais e orientações clínicas. 
- Durante o nono e décimo semestres (quinto ano), os alunos terão um período semanal de atividades, correspondentes a 192 horas/ano, no qual realizarão, sob supervisão, assistência médica nas Unidades ou em visitas domiciliares, integrando a ESF na condição de médico de família em treinamento.

A disciplina no primeiro ano de graduação propõe como objetivos:

- Formar uma mentalidade na prática assistencial pautada nos princípios da cidadania, no reconhecimento da autonomia dos usuários, na interação com a população e com a equipe de saúde, na busca de soluções para os problemas identificados e no envolvimento com os resultados da assistência;

- Reconhecer a história social da doença e o Programa de Saúde da Família (PSF) como modalidade de assistência à saúde;

- Promover o desenvolvimento de habilidades e padrões de comportamento voltados para o envolvimento com os problemas de saúde da comunidade no plano individual e coletivo, e na relação profissional/usuário baseada na alteridade e na responsabilidade social.

A disciplina, no terceiro ano de graduação, propõe como objetivos:

\section{Área cognitiva}

- Interagir na equipe multiprofissional, planejando e participando das atividades em grupo;

- Fazer o levantamento epidemiológico da região, listar os principais agravos e discutir propostas de resolução desses problemas; integrar essas informações ao atendimento individual ou em grupo dentro do Programa de Saúde da Família;

- Realizar consultas com enfoque preventivo e de promoção da saúde, incluindo informações sobre hábitos de vida, vacinas e rastreamento de doenças.

\section{Área psicomotora - habilidades}

- Acompanhar o atendimento na Unidade Básica de Saúde;

- Participar das atividades em grupo promovidas pela Unidade Básica de Saúde.

Área afetiva - atitudes

- Assistir a família e seus integrantes nas queixas mais simples e problemas mais prevalentes em consultas na UBS ou em visitas domiciliares;
- Reconhecer fatores ambientais e psicossociais como determinantes das doenças;

- Desempenhar um papel educativo nas visitas domiciliares e nos grupos;

- Valorizar o controle periódico dos principais problemas de saúde nos vários ciclos de vida.

\section{Avaliação dos alunos nas disciplinas}

Os alunos do primeiro ano são avaliados em quatro momentos: por meio de um relatório ao término do período de visitas domiciliares, no qual descrevem e avaliam criticamente as visitas domiciliares realizadas; discussão em grupo e elaboração de prova individual sobre uma situação de vida real de uma das localidades, descrita com proteção de identidades; relatório das ações de saúde realizadas e resultados prévios encontrados; e, por fim, elaboração de uma questão de aprendizagem resultante das ações de saúde e sua resposta baseada em pesquisa referenciada (bibliografia). As percepções e observações dos alunos são sistematizadas em relatórios, utilizados para avaliação continuada. A finalidade destes é promover a narrativa dos fatos observados.

O terceiro ano de graduação tem sua avaliação promovida pela elaboração e discussão de pôsteres, apresentados ao final do semestre, que descrevem criticamente as situações de vida e os processos de acompanhamento dos grupos de alunos com as ESF.

\section{Avaliação das disciplinas pelos alunos}

As disciplinas foram avaliadas por meio de questionário de avaliação de ambiente (DREEM), por questionário modificado de Delphi, auto-avaliação durante provas finais e em fóruns semestrais durante o andamento das atividades didáticas.

Os objetivos propostos foram auto-avaliados por meio de uma escala de capacidades. As afirmações apresentadas na escala coincidem com os objetivos propostos no início da disciplina. Cada objetivo pode ser considerado pelo aluno pelos escores como a seguir:

\section{Escore Definição}

0 Não sei nada sobre o assunto/procedimento.

1 Li a respeito ou fui informado de como fazer.

$2 \quad$ Vi alguém fazendo o procedimento.

3 Fiz o procedimento com ajuda de algum orientador.

$4 \quad$ Fiz o procedimento corretamente sozinho.

5 Fiz o procedimento tantas vezes e com tal segurança que posso orientar.

De forma complementar, o questionário Delphi, determinado durante o ano de 2004, solicitou aos estudantes 
do primeiro ano que respondessem quais qualificações acreditavam ter adquirido na disciplina. As 20 respostas mais freqüentes foram compiladas e oferecidas para uma seleção das cinco mais importantes em ordem de preferência, realizada no mesmo ano de 2004 e para posterior seguimento a ser oferecido nos anos subseqüentes entre alunos do primeiro ano. As escolhas receberam fatores $1,0,75,0,50,0,25$ e 0,10 para seqüência da primeira à quinta preferência. A soma das respostas ponderadas pelos fatores determinou os escores de prioridades para as qualificações.

O questionário DREEM de avaliação de ambiente contém 50 questões com respostas do tipo Likert (cinco respostas com progressão de pouco a muito). Versão em português foi utilizada em estudo anterior em que foram observados cinco domínios de percepções, Aprendizado, Professores, Acadêmico, Ambiente e Social Própria, comparados com o padrão do estudo original "Dundee"2,3.

Todas as disciplinas da Faculdade de Medicina são avaliadas em fóruns semestrais em horário protegido. Para tanto, são convidados os professores coordenadores das disciplinas oferecidas no semestre em vigência, professores participantes e alunos. Estas atividades são separadas em fóruns do primeiro e segundo anos, do terceiro e quarto, e do internato - quinto e sexto. Têm seu registro elaborado por um relator e enviado à Comissão de Graduação da Unidade.

\section{RESULTADOS}

A disciplina foi oferecida como optativa no segundo semestre de 2003. A avaliação desta atividade ocorreu com fórum no qual foram propostas atividades para implantação regular no primeiro ano do curso médico a partir de 2004. Em decorrência destas discussões, as atividades foram modificadas, constituindo três grades entre os anos de 2004 a 2006 (Quadro 1), que permitem observar as modificações propostas pelos alunos.

As avaliações finais foram oferecidas a todos os alunos, exceto em 2006, ainda em andamento, e o questionário Delphi para 2005. Cento e sessenta e dois primeiranistas em 2004 (93\%), 142 em 2005 (81\%) e 129 terceiranistas (74\%) responderam os questionários. Estes alunos do terceiro ano constituem a classe de matriculados em 2003 e que não tiveram a experiência da disciplina durante o primeiro ano médico.

Os objetivos alcançaram nível 3 - "fiz o procedimento com ajuda de_alguém" - para: orientar a utilização dos Serviços de Saúde, visitar famílias para informar sobre saúde, identificar situações de risco, visitar famílias para promover saúde, visitar famílias para oferecer suporte (Figura 1). Os objetivos "consulta médica com adultos" e "reunião de grupo com pacientes" também foram considerados no nível 3 entre terceiranistas (Figura 2).

As qualificações adquiridas na disciplina foram: entender a realidade social e de saúde, familiarizar-se com o trabalho do agente comunitário, entender o Programa de Saúde da Família, entender Atenção Primária, ter proximidade com a comunidade local, conhecer o Sistema de Saúde, visão crítica (Figura 3).

As percepções do DREEM foram diferenciadas entre os locais ou equipes em que se originaram. Todos os valores foram inferiores ao considerado padrão "Dundee", exceto as percepções entre primeiranistas Professores e Social Própria para a turma B, em 2004, e Professores para a UBS Vila Dalva, turma A, em 2005. Algumas percepções atingiram uma diferença superior a $10 \%$ entre os grupos ou entre locais, sugerindo que o DREEM tem sensibilidade entre equipes ou locais de atividades práticas (Tabela 1).

\section{DISCUSSÃO}

A evolução do programa de Atenção Básica em Saúde demonstrou interesse e participação do conjunto de alunos da FMUSP no aprimoramento da própria disciplina. As avaliações das atividades práticas sugerem razoável capacitação discente junto ao trabalho desenvolvido pelos agentes comunitários. Sistema de Saúde, Programa de Saúde da Família e Atenção Básica em Saúde tornaram-se parte do vocabulário na auto-avaliação dos alunos.

Estudo anterior sugerira que os estudantes de Medicina da USP declaravam insuficiência no treinamento em Atenção Primária e no trabalho em Equipes de Saúde, além de um limitado conhecimento sobre o SUS4 4 . A Faculdade de Medicina da USP decidiu abordar a organização do sistema de saúde com a exposição à prática logo no início do curso médico, durante o terceiro ano e no internato, adotando como cenário de prática o Programa de Saúde da Família.

Pode ser interessante observar como as ações de saúde alcançaram maior confiança na auto-avaliação (nível 3 em 5). Por outro lado, temas socioeconômicos, como "observar funcionamento da comunidade" ou "levantamento de condições de vida", foram pouco apreciados, atingindo somente nível 1 - Li a respeito ou fui informado de como fazer -, sugerindo que estudantes ainda não percebem o modo de vida da população local. Esta ausência pode ser resultado de falha da disciplina na utilização da prática de Visitas Domiciliares (VD), notadamente considerando que os dados se referem às duas primeiras edições da disciplina. De fato, $\mathrm{o}$ Quadro 1 permite observar que, a partir de 2006, as VDs recebem aporte teórico com aula de antropologia urbana no 
período de realização destas. Nos anos anteriores, esse aporte ocorrera após tais atividades, com provável prejuízo do vínculo na observação prática da realidade local.

As VDs, juntamente com os planejamentos de intervenção nas comunidades observadas, representam, segundo avaliações dos fóruns dos alunos, momentos de grande interesse pela disciplina. Na concepção de 2006, cada período de VD é seguido de um período para discussão das situações clínicas observadas. Há reconhecimento de que o melhor momento deveria ser imediatamente após as observações das VDs. No entanto, em decorrência da realidade da metrópole paulistana e do respeito ao horário da grade (quatro horas por período), a discussão ocorre, em cada grupo, no período (semana) subseqüente.

A elaboração dos relatórios (avaliação formativa) como narrativas aproxima o aluno, futuro médico, do mundo do paciente de modo indelével. As situações de vida, de saúde e de doença, com seus cuidados, têm maiores chances de serem apreendidas pelos alunos observadores e participantes quando da elaboração e crítica por meio de textos avaliados. Assim, espera-se aumentar a habilidade de enxergar e compreender o outro 5 .

As percepções do DREEM originadas em locais ou equipes distintas mostraram-se diferenciadas. Algumas percepções atingiram uma diferença superior a $10 \%$ entre os grupos ou entre locais. Na presente disciplina, que utiliza uma equipe de 12 professores, além dos profissionais de saúde das UBS, essa sensibilidade é importante para auxiliar no alcance e planejamento da disciplina e sua homogeneização em termos de engajamento de professores. Pode ser razoável supor que as UBS tenham diferentes formas de lidar com as inúmeras variáveis, mas as discussões promovidas pelos docentes após as VDs devem se ater às implicações dos objetivos da disciplina, notadamente à proposta de considerar uma história social da saúde e da doença.

A disciplina evoluiu entre as três edições a partir das críticas dos alunos, embora os instrumentos de avaliação da disciplina preenchidos pelos alunos não tenham mostrado diferenças importantes. Eventualmente, a observação mais afetada pode ter sido o levantamento das condições de vida (Figura 1), mais bem pontuado na edição de 2005. Assim, o estudo de cadastros familiares e mapas regionais foi superado pela prática das visitas com ACS, nas quais os cadastros são observados e discutidos. Outras atividades, como a observação de consultas e encontros agendados com gestores locais, na edição de 2004, mostraram-se impraticáveis. A relação aluno/consultório seria muito elevada e desconfortável para todos, médicos, pacientes e alunos. Mesmo a substituição pela observação de uma consulta pela Equipe de Saúde da Família - enfermagem, psicologia ou outro profissional da UBS - esbarrara em agendas ou superdimensionamentos.

Quanto aos gestores locais, a disponibilidade de agenda compatível com a grade curricular mostrou-se um grande empecilho para a efetivação desta atividade. No entanto, dado o possível alcance desta atividade na formação de profissionais mais participativos e informados sobre a formulação e implementação da política de saúde, ainda se busca uma solução viável para manter esta possibilidade de diálogo entre futuros profissionais e gestores de saúde.

O curso de Medicina tem um propósito bastante vocacional. Há, assim, uma clara intenção de dar ao estudante uma interpretação realista da prática médica. As disciplinas eletivas podem ser um meio de permitir que os estudantes desenvolvam seus próprios projetos, mesmo na experiência de uma especialização bastante específica ${ }^{6}$. Em recente estudo, constatou-se que as disciplinas optativas mais procuradas pelos estudantes foram aquelas relacionadas ao desenvolvimento de habilidades práticas ${ }^{7}$. A disciplina de Atenção Básica procura utilizar esta observação ao propor mais tempo em atividades práticas de visitas domiciliares.

Esse propósito também foi aproveitado na concepção da disciplina, permitindo que os alunos desenvolvam, em conjunto com as equipes de agentes comunitários, projetos de intervenção na comunidade. De maneira resumida, os projetos se dirigiram para encontros com alunos da rede municipal no tratamento de questões como cuidados com a saúde e sexualidade, com grupos de moradores para programas de nutrição, com associações de moradores para organização de coletas seletivas e de materiais recicláveis, com os próprios agentes comunitários em programas de suporte a seu trabalho (grupos de apoio) e também pelo seguimentoacolhimento de famílias.

Os estudantes apontaram o envolvimento com a realidade social e de saúde local e as tarefas dos agentes comunitários, também moradores locais, como capacitações obtidas no desenvolvimento da disciplina. Também é interessante observar que se declaram aptos a identificar áreas de risco e de condições de vida. As propostas de entender a Atenção Primária e o Sistema de Saúde exigem maior atenção, pois receberam baixa avaliação em 2004 e 2005. Na evolução da disciplina, em 2006 foram introduzidas aulas sobre os temas, além de se procurar enfatizá-los nas discussões das VDs (Figura 3).

O papel dos diversos serviços de saúde tem sido buscar prevenir e tratar as doenças, manter a saúde e investigar os determinantes do processo saúde/doença. Pode-se considerar como extensão deste papel a promoção da saúde e da vida 
saudável, a humanização no tratamento de doentes e a inovação diagnóstica e terapêutica como resultado da investigação. $\mathrm{O}$ estudo de condições de vida pode revelar maior identidade com grupos sociais. Assim, o resultado pode ser a pretensão do serviço de saúde de se propor como o interlocutor de demandas ou mesmo o tradutor político de grupamentos pouco organizados.

Não será surpreendente, portanto, encontrar a medicina tentando definir necessidades de grupamentos sociais. No entanto, pode-se supor que, quando médicos tentam definir necessidades sociais que não as suas próprias, não estarão comunicando reivindicações legítimas desses grupos sociais. Essa referência entre grupos sociais - médicos de um lado e comunidade de outro - pode resultar em conflitos que antecedem os conflitos "naturais" entre forças sociais quando do embate por demandas legítimas.

A escola médica deverá assumir as necessidades sociais originadas nos e definidas pelos grupos locais, aliando técnica e sensibilidade política. A técnica parece ser o meio mais claro que a escola médica tem para transmitir a capacidade resolutiva em qualquer nível da atenção à saúde. A definição clara de objetivos a serem alcançados para conceitos, comportamentos e atitudes permite que docentes e estudantes tenham clareza da formação até seu momento de avaliação. Adquirindo sensibilidade, a cultura deixa de ser desigual para tornar-se diferente. Com esse conceito, o médico não mais procura eliminar a distância entre sua atuação e o desejo do paciente, ou tornar o desigual em igual, mas entendê-la, como diferentes que são e conscientes dessa diferença e de sua participação social. A ética propõe que o relacionamento médico-paciente se oriente pela solidariedade, que permite o diálogo para o reconhecimento da cidadania e da diferença ${ }^{8}$.

Finalmente, deve-se notar que a disciplina não tem ficado imune a várias e importantes críticas. É interessante notar como os alunos declaram, nos fóruns de 2004, sua insatisfação com a "falta de objetivos", embora todos sejam descritos na ementa da disciplina, e suas avaliações de qualificações adquiridas traduzam esses mesmos objetivos. Aparentemente, é possível que esteja sendo criticada a ausência de objetivos de habilidades, eventualmente manuais. A disciplina propõe objetivos que poderiam ser, com ousadia, associados ao "complexo prazer do pensamento", citado por Borges".

Em conclusão, a disciplina de Atenção Básica em Saúde encontra, até o presente, boa aceitação entre discentes, considerando o ambiente dominante da Faculdade de Medicina da USP, onde a especialização se mostra bastante atraente. A complexidade da disciplina deve ser entendida como uma complexidade de conceitos, bem como de processos assistenciais, em contraposição à complexidade tecnológica encontrada em hospitais de grande porte. A principal motivação, que é o seguimento de pessoas e famílias em comunidades, deverá ser plena com a instalação da disciplina no internato. Nesse período, as avaliações devem endereçar o aproveitamento do programa para o alcance do conceito de história social das doenças, da promoção da saúde e prevenção de doenças nos ambientes de convívio, na assistência às demandas e necessidades por saúde da população e na educação permanente em saúde como estratégia de trabalho em Equipes de Saúde da Família nas Unidades Básicas de Saúde.

\section{REFERENNCIAS}

1. Ministério da Educação. Conselho Nacional de Educação. Câmara de Educação Superior. Resolução CNE/CES nº 4, de 7 de novembro de 2001. Institui diretrizes curriculares nacionais do curso de graduação em Medicina. [online]. Brasília, DF; 2001. [capturado 14 jun. 2006]. Disponível em: http:/ / portal.mec.gov.br/cne/arquivos/pdf/CES04.pdf.

2. Vieira JE, Nunes MPT, Martins MA. Directing student response to early patient contact by questionnaire. Med Educ. 2003; 37(2): 119-25.

3. Roff S, McAleer S, Harden RM. Development and validation of the Dundee Ready Education Environment Measure (DREEM). Med Teach. 1997; 19: 295-99.

4. Vieira JE, Lopes Júnior A, Basile MA, Martins MA. Identificação das diretrizes curriculares nacionais do curso de graduação em Medicina pelos alunos da Universidade de São Paulo. Rev Bras Educ Med. 2003; 27(2): 96-103.

5. Grossman E, Cardoso MHCA. As narrativas em medicina: contribuições à prática clínica e ao ensino médico. Rev Bras Educ Med. 2006; 30(1): 6-14.

6. Eddleston A, Booton P. The undergraduate medical course. Med Educ. 1997; 31(suppl. 1): 7-9.

7. Vieira JE, Bellodi PL, Marcondes E, Martins MA. Atividades práticas dirigem escolha de disciplinas eletivas no curso médico. Rev Bras Educ Med. 2005; 29(1): 51-4.

8. Vieira JE. Definição de necessidades sociais para o ensino médico. Rev Bras Educ Med. 2003; 27(2): 153-7.

9. Borges JL. O Aleph. São Paulo: Globo; 2003. Cap.: O Imortal.

\section{CONFLITO DE INTERESSE}

Os autores do referido artigo são professores ou profissionais médicos contratados pela instituição de ensino - 
Faculdade de Medicina da USP e seu Hospital de ensino onde a disciplina descrita se desenvolve. Os autores não receberam nenhum patrocínio de qualquer empresa ou instituição de qualquer porte ou área de atuação para realização deste estudo em qualquer fase do mesmo.

\section{ENDEREÇO PARA CORRESPONDÊNCIA}

Joaquim Edson Vieira

Av. Dr. Arnaldo 455, sala 2342

São Paulo, SP, 01246-903

e-mail: joaquimev@usp.br

\section{QUADRO 1}

Modificação das atividades didáticas locais em Unidades Básicas de Saúde no período de 2004 a 2006 e número de semanas utilizadas

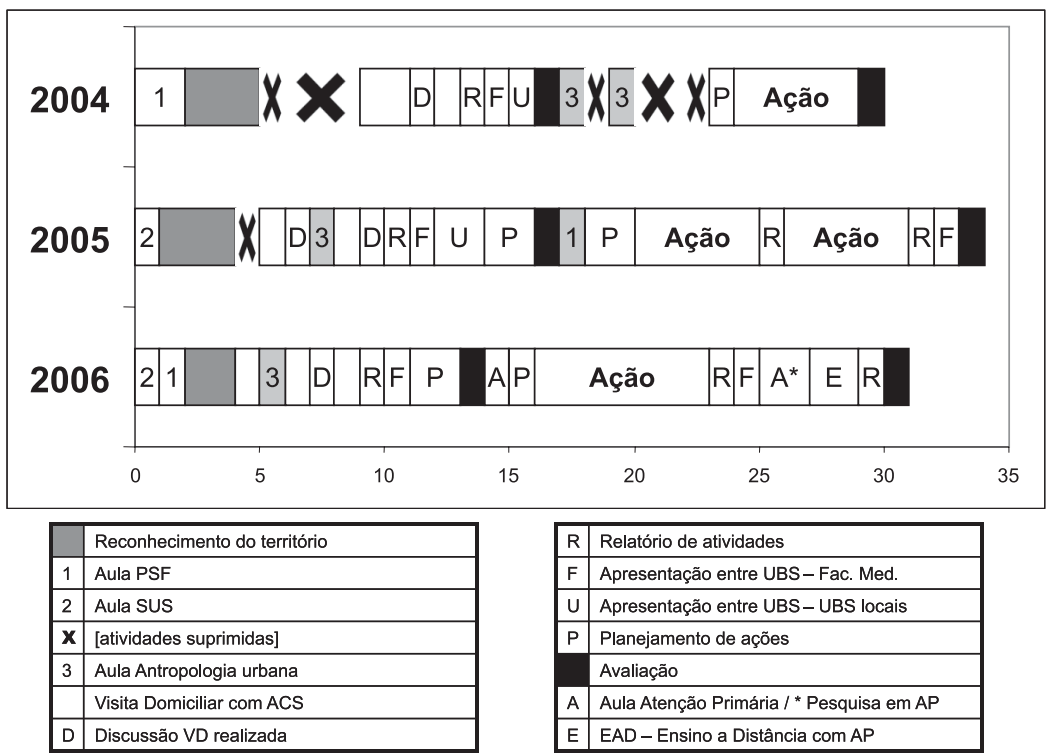

Figura 1.

Auto-avaliação entre alunos de primeiro ano para objetivos da Disciplina de Atenção Primária em Saúde.

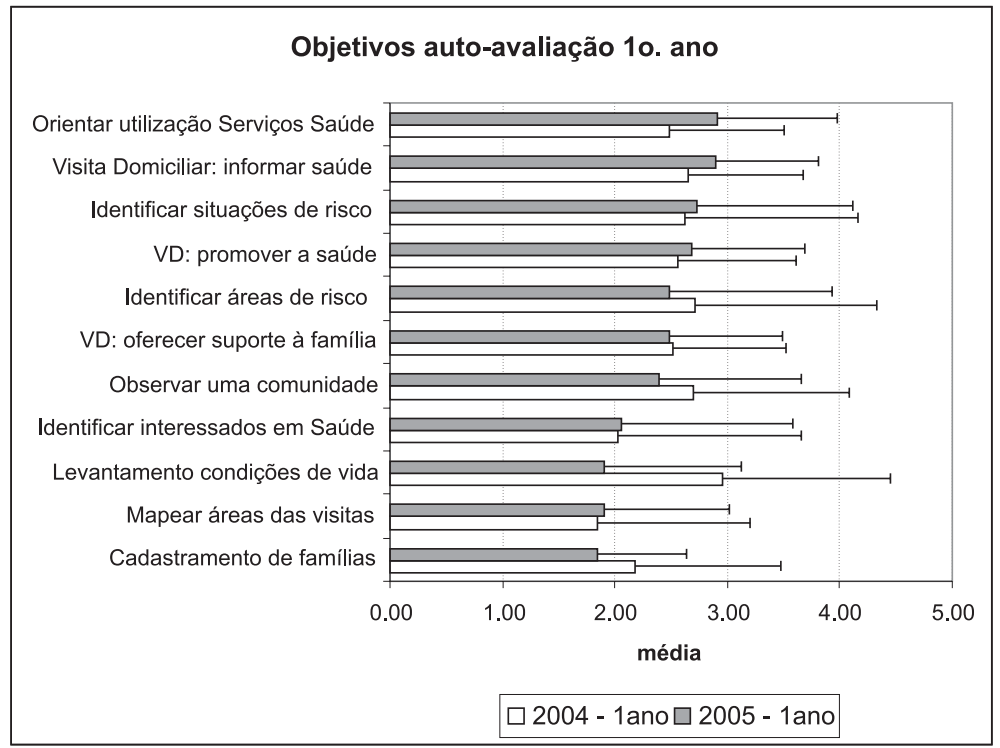


Figura 2.

Auto-avaliação entre alunos de terceiro ano para objetivos da Disciplina de Atenção Primária em Saúde.

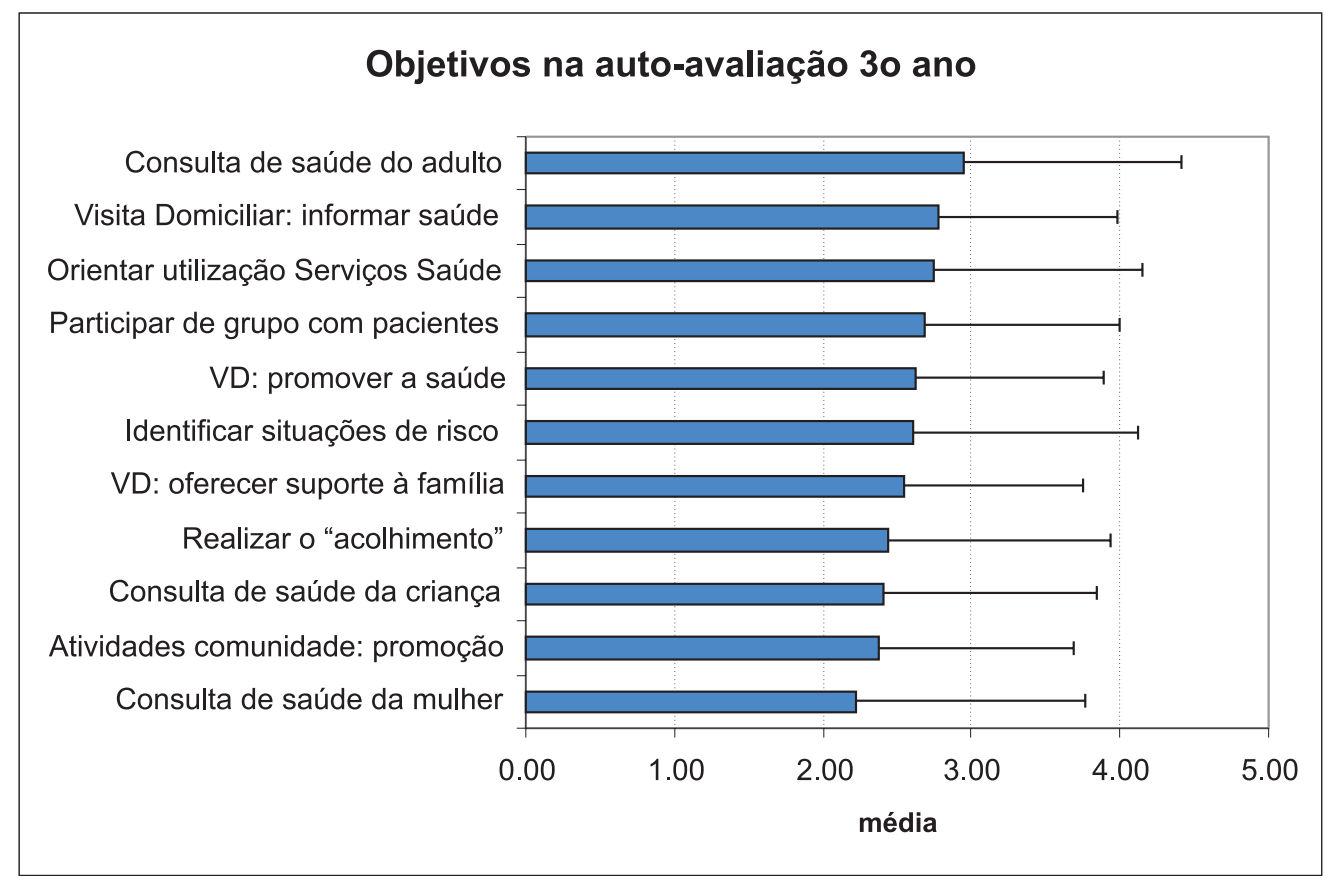

TABELA 1

Domínios do DREEM entre as UBS, entre o primeiro e terceiro ano, e considerando o padrão Dundee

\begin{tabular}{|c|c|c|c|c|c|c|}
\hline Dundee & & $\sqrt{65,8}$ & 65,8 & 64,3 & 68,6 & 65,4 \\
\hline & & Aprendizado & Professores & Acadêmica & Ambiente & Social própria \\
\hline \multicolumn{7}{|c|}{2005} \\
\hline \multirow{10}{*}{ Primeiro ano } & Bvista A & 56,2 & 63,2 & 62,8 & 59,9 & 62,8 \\
\hline & Bvista B & 45,3 & 54,9 & 51,3 & 50,1 & 53,7 \\
\hline & Bvista A-B & 10,9 & 8,3 & 11,5 & 9,8 & 9,1 \\
\hline & Dalva A & 55 & $66,8^{*}$ & 55 & 59 & 63,2 \\
\hline & Dalva B & 49,9 & 58,8 & 55,9 & 56,6 & 54,4 \\
\hline & Dalva A-B & 5,1 & 8 & $-0,9$ & 2,4 & 8,8 \\
\hline & Sjorge A & 51,1 & 65,3 & 56,8 & 60,8 & 59,8 \\
\hline & Sjorge B & 52,6 & 57,9 & 56 & 56,2 & 57,1 \\
\hline & Sjorge A-B & $-1,5$ & 7,4 & 0,8 & 4,6 & 2,7 \\
\hline & $\begin{array}{l}\text { Maiores } \\
\text { diferenças }\end{array}$ & 10,9 & 11,9 & 11,5 & 10,7 & 9,5 \\
\hline M 1ㅇ ano & & 51,7 & 61,2 & 56,3 & 57,1 & 58,5 \\
\hline $3^{\circ}$ ano & & 48,5 & 59,8 & 57,1 & 57,3 & 60,4 \\
\hline \multicolumn{7}{|c|}{2004} \\
\hline \multirow[t]{3}{*}{ Primeiro ano } & Turma A & 46 & 54 & 53 & 58 & 61 \\
\hline & Turma B & 60 & $71^{*}$ & 60 & 66 & $69^{*}$ \\
\hline & Turma A-B & 14 & 17 & 7 & 8 & 8 \\
\hline $\mathrm{M} 1^{\circ}$ ano & & 53 & 62 & 56 & 62 & 65 \\
\hline
\end{tabular}

*Valores acima do padrão "Dundee". 
Figura 3.

Qualificações adquiridas na disciplina de Atenção Primária (2004).

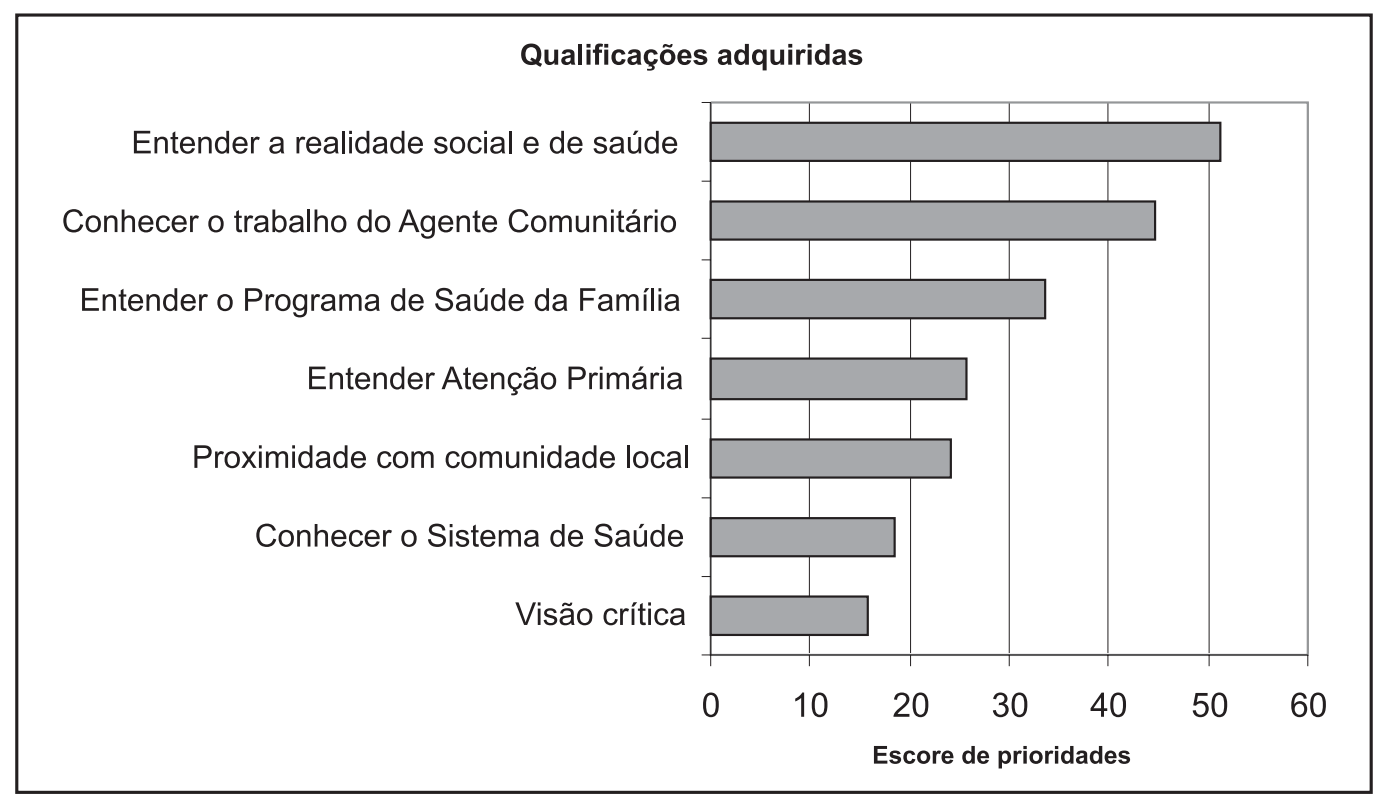

